\title{
Other Business and Financial Operations Workers
}

National Cancer Institute

\section{Source}

National Cancer Institute. Other Business and Financial Operations Workers. NCI

Thesaurus. Code C122537.

Business and financial operations workers not specifically identified elsewhere. 